\title{
Aluminium matrix composites: Challenges and opportunities
}

\author{
M K SURAPPA
}

Department of Metallurgy, Indian Institute of Science, Bangalore 560 012, India e-mail: mirle@metalrg.iisc.ernet.in

\begin{abstract}
Aluminium matrix composites (AMCs) refer to the class of light weight high performance aluminium centric material systems. The reinforcement in AMCs could be in the form of continuous/discontinuous fibres, whisker or particulates, in volume fractions ranging from a few percent to $70 \%$. Properties of AMCs can be tailored to the demands of different industrial applications by suitable combinations of matrix, reinforcement and processing route. Presently several grades of AMCs are manufactured by different routes. Three decades of intensive research have provided a wealth of new scientific knowledge on the intrinsic and extrinsic effects of ceramic reinforcement vis-a-vis physical, mechanical, thermo-mechanical and tribological properties of AMCs. In the last few years, AMCs have been utilised in high-tech structural and functional applications including aerospace, defence, automotive, and thermal management areas, as well as in sports and recreation. It is interesting to note that research on particle-reinforced cast AMCs took root in India during the 70's, attained industrial maturity in the developed world and is currently in the process of joining the mainstream of materials. This paper presents an overview of AMC material systems on aspects relating to processing, microstructure, properties and applications.
\end{abstract}

Keywords. Aluminium matrix composites; processing of AMCs; microstructure; applications of AMCs.

\section{Introduction}

The term "composite" broadly refers to a material system which is composed of a discrete constituent (the reinforcement) distributed in a continuous phase (the matrix), and which derives its distinguishing characteristics from the properties of its constituents, from the geometry and architecture of the constituents, and from the properties of the boundaries (interfaces) between different constituents. Composite materials are usually classified on the basis of the physical or chemical nature of the matrix phase, e.g., polymer matrix, metal-matrix and ceramic composites. In addition there are some reports to indicate the emergence of Inter metallic-matrix and carbon-matrix composites. This review is concerned with metal matrix composites and more specifically on the aluminium matrix composites (AMCs). In AMCs one of the constituent is aluminium/aluminium alloy, which forms percolating network and is termed as matrix phase. The other constituent is embedded in this aluminium/aluminium alloy 
matrix and serves as reinforcement, which is usually non-metallic and commonly ceramic such as $\mathrm{SiC}$ and $\mathrm{Al}_{2} \mathrm{O}_{3}$. Properties of AMCs can be tailored by varying the nature of constituents and their volume fraction.

The major advantages of AMCs compared to unreinforced materials are as follows:

- Greater strength

- Improved stiffness

- Reduced density(weight)

- Improved high temperature properties

- Controlled thermal expansion coefficient

- Thermal/heat management

- Enhanced and tailored electrical performance

- Improved abrasion and wear resistance

- Control of mass (especially in reciprocating applications)

- Improved damping capabilities.

These advantages can be quantified for better appreciation. For example, elastic modulus of pure aluminium can be enhanced from 70GPa to 240GPa by reinforcing with 60 vol.\% continuous aluminum fibre. On the other hand incorporation of $60 \mathrm{vol} \%$ alumina fibre in pure aluminium leads to decrease in the coefficient of expansion from $24 \mathrm{ppm} /{ }^{\circ} \mathrm{C}$ to $7 \mathrm{ppm} /{ }^{\circ} \mathrm{C}$. Similarly it is possible to process Al-9\% $\mathrm{Si}-20 \mathrm{vol} \% \mathrm{SiCp}$ composites having wear resistance equivalent or better than that of grey cast iron. All these examples illustrate that it is possible to alter several technological properties of aluminium/aluminium alloy by more than twothree orders of magnitude by incorporating appropriate reinforcement in suitable volume fraction.

AMC material systems offer superior combination of properties (profile of properties) in such a manner that today no existing monolithic material can rival. Over the years, AMCs have been tried and used in numerous structural, non-structural and functional applications in different engineering sectors. Driving force for the utilisation of AMCs in these sectors include performance, economic and environmental benefits. The key benefits of AMCs in transportation sector are lower fuel consumption, less noise and lower airborne emissions. With increasing stringent environmental regulations and emphasis on improved fuel economy, use of AMCs in transport sector will be inevitable and desirable in the coming years.

AMCs are intended to substitute monolithic materials including aluminium alloys, ferrous alloys, titanium alloys and polymer based composites in several applications. It is now recognized that in order AMCs substitution for monolithic materials in engineering system to be wide spread, there is a compelling need to redesign the whole system to gain additional weight and volume savings. In fact according to the UK Advisory Council on Science and Technology, AMCs can be viewed either as a replacement for existing materials, but with superior properties, or as a means of enabling radical changes in system or product design. Moreover, by utilising near-net shape forming and selective-reinforcement techniques AMCs can offer economically viable solutions for wide variety of commercial applications.

Recent success in commercial and military applications of AMCs are based partly on such innovative changes made in the component design. Lack of knowledge and information about utilisation possibilities, service properties and material producers have hindered the wider usage of AMCs. Recognising these peripheral and extraneous difficulties, AMCs community in USA and Europe are pursuing consortium and networking approaches to implement the applications of AMCs in everyday societal use. In this article, overview is given on the current state of art on aluminium matrix composites with regard to processing, microstructure, 
properties and applications of AMCs. Challenges and opportunities for the intense use of AMCs are also outlined.

\section{Types of AMCs}

AMCs can be classified into four types depending on the type of reinforcement.

(a) Particle-reinforced AMCs (PAMCs)

(b) Whisker-or short fibre-reinforced AMCs (SFAMCs)

(c) Continuous fibre-reinforced AMCs (CFAMCs)

(d) Mono filament-reinforced AMCs (MFAMCs)

Some of the salient features of these four types of AMCs are detailed below.

\subsection{Particle reinforced aluminium matrix composites (PAMCs)}

These composites generally contain equiaxed ceramic reinforcements with an aspect ratio less than about 5. Ceramic reinforcements are generally oxides or carbides or borides $\left(\mathrm{Al}_{2} \mathrm{O}_{3}\right.$ or $\mathrm{SiC}$ or $\mathrm{TiB}_{2}$ ) and present in volume fraction less than $30 \%$ when used for structural and wear resistance applications. However, in electronic packaging applications reinforcement volume fraction could be as high as $70 \%$. In general, PAMCs are manufactured either by solid state (PM processing) or liquid state (stir casting, infiltration and in-situ) processes. PAMCs are less expensive compared to CFAMCs. Mechanical properties of PAMCs are inferior compared to whisker/short fibre/continuous fibre reinforced AMCs but far superior compared to unreinforced aluminium alloys. These composites are isotropic in nature and can be subjected to a variety of secondary forming operations including extrusion, rolling and forging. Figure 1a shows the microstructure of cast aluminium matrix composite having high volume fraction (40 vol\%) SiC particle reinforcements.

\subsection{Short fibre- and whisker-reinforced aluminium matrix composites (SFAMCs)}

These contain reinforcements with an aspect ratio of greater than 5, but are not continuous. Short alumina fibre reinforced aluminium matrix composites is one of the first and most popular AMCs to be developed and used in pistons. These were produced by squeeze infiltration process. Figure $1 \mathrm{~b}$ shows the microstructure of short fibre reinforced AMCs. Whisker reinforced composites are produced by either by PM processing or by infiltration route. Mechanical properties of whisker reinforced composites are superior compared to particle or short fibre reinforced composites. However, in the recent years usage of whiskers as reinforcements in AMCs is fading due to perceived health hazards and, hence of late commercial exploitation of whisker reinforced composites has been very limited. Short fibre reinforced AMCs display characteristics in between that of continuous fibre and particle reinforced AMCs.

\subsection{Continuous fibre-reinforced aluminium matrix composites (CFAMCs)}

Here, the reinforcements are in the form of continuous fibres (of alumina, $\mathrm{SiC}$ or carbon) with a diameter less than $20 \mu \mathrm{m}$. The fibres can either be parallel or pre woven, braided prior to the production of the composite. AMCs having fibre volume fraction upto $40 \%$ are produced by squeeze infiltration technique. More recently $3 \mathrm{M}^{\mathrm{Tm}}$ corporation has developed $60 \mathrm{vol} \%$ 
(a)

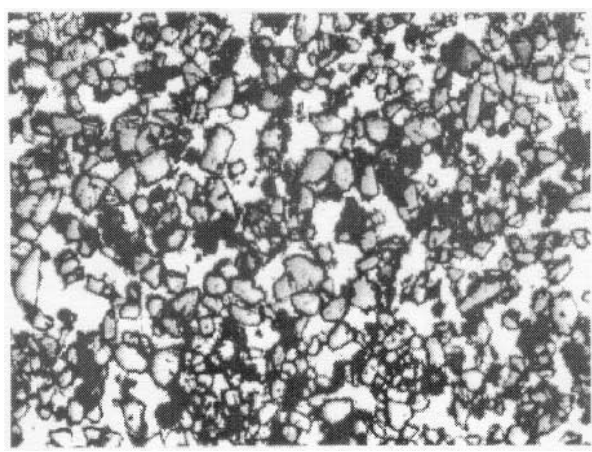

(c)

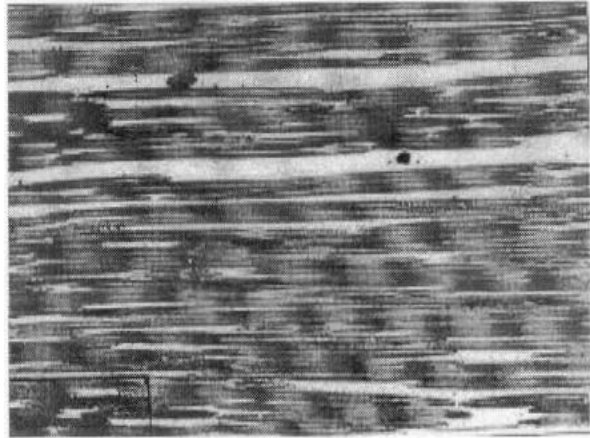

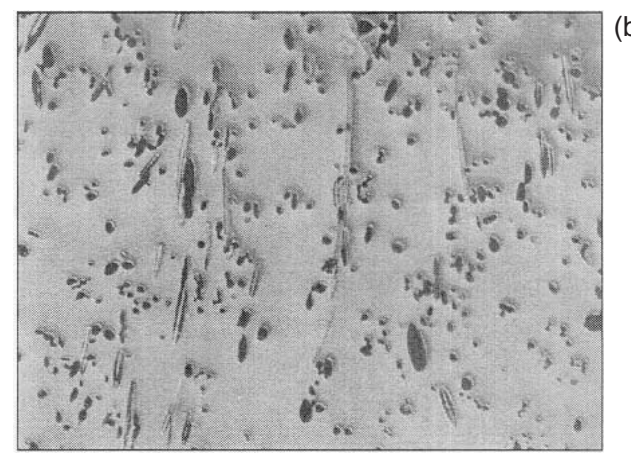

(b)

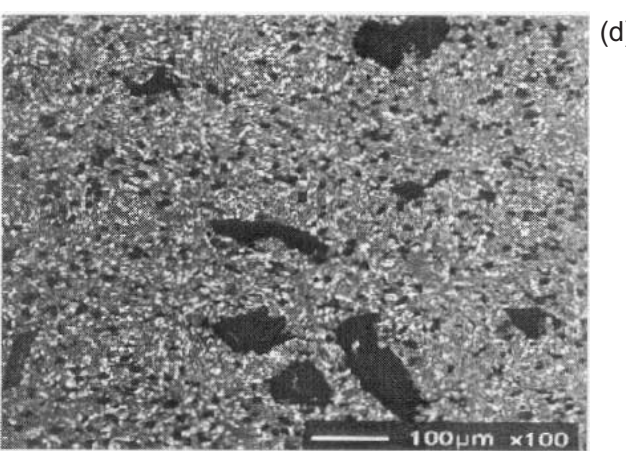

Figure 1. Microstructures of (a) aluminium matrix composite having high volume fraction of $\mathrm{SiC}$ particle reinforcement (40 vol\%), (b) short fibre-reinforced aluminium matrix composite, (c) continuous fibre-reinforced aluminium matrix composite, (d) hybrid composite containing $10 \% \mathrm{SiC}$ and $4 \%$ graphite particles.

alumina fibre (continuous fibre) reinforced composite having a tensile strength and elastic stiffness of $1500 \mathrm{MPa}$ and $240 \mathrm{GPa}$ respectively. These composites are produced by pressure infiltration route. Figure $1 \mathrm{c}$ shows the microstructure of continuous fibre (alumina) reinforced AMCs.

\subsection{Mono filament reinforced aluminium matrix composites (MFAMCs)}

Monofilaments are large diameter $(100$ to $150 \mu \mathrm{m})$ fibres, usually produced by chemical vapour deposition (CVD) of either $\mathrm{SiC}$ or $\mathrm{B}$ into a core of carbon fibre or $\mathrm{W}$ wire. Bending flexibility of monofilaments is low compared to multifilaments. Monofilament reinforced aluminium matrix composites are produced by diffusion bonding techniques, and is limited to super plastic forming aluminium alloy matrices.

In CFAMCs and MFAMCs, the reinforcement is the principal load-bearing constituent, and role of the aluminium matrix is to bond the reinforcement and transfer and distribute load. These composites exhibit directionality. Low strength in the direction perpendicular to the fibre orientation is characteristic of CFAMCs and MFAMCs. In particle and whisker reinforced AMCs, the matrix is the major load-bearing constituent. The role of the reinforcement is to strengthen and stiffen the composite by preventing matrix deformation by mechanical restraint.

In addition to four types of AMCs described above, another variant of AMCs known as hybrid AMCs have been developed and are in use to some extent. Hybrid AMCs essentially 
contain more than one type of reinforcement. For example, mixture of particle and whisker, or mixture of fibre and particle or mixture of hard and soft reinforcements. Aluminium matrix composite containing mixture of carbon fibre and alumina particles used in cylindrical liner applications is an example of hybrid composite. Figure 1d shows microstructure of hybrid AMC having both hard $\mathrm{SiC}$ and soft graphite particles as reinforcement.

\section{Primary processing of AMCs}

Primary processes for manufacturing of AMCs at industrial scale can be classified into two main groups.

(1) Solid state processes.

(2) Liquid state processes.

Powder blending followed by consolidation (PM processing), diffusion bonding and vapour deposition techniques come under solid state processing. Liquid state processes include stir casting or compo casting, infiltration, spray casting and in situ (reactive) processing. The selection of the processing route depends on many factors including type and level of reinforcement loading and the degree of microstructural integrity desired. Table 1 provides feasibility of various primary processes for manufacturing different types of AMCs. It is evident from the table 1, that very often it is possible to manufacture AMC of specific formulation (having the same matrix and reinforcement combination) by more than one route.

\subsection{Solid state processing}

3.1a Powder blending and consolidation (PM processing): Blending of aluminium alloy powder with ceramic short fibre/whisker particle is versatile technique for the production of AMCs. Blending can be carried out dry or in liquid suspension. Blending is usually followed by cold compaction, canning, degassing and high temperature consolidation stage such as hot isostatic pressing (HIP) or extrusion. PM processed AMCs, contain oxide particles in the form of plate-like particles of few tens of $\mathrm{nm}$ thick and in volume fractions ranging from 0.05 to 0.5 depending on powder history and processing conditions. These fine oxide particles tends to act as a dispersion-strengthening agent and often has strong influence on the matrix properties particularly during heat treatment.

3.1b Diffusion bonding: Mono filament-reinforced AMCs are mainly produced by the diffusion bonding (foil-fibre-foil) route or by the evaporation of relatively thick layers of aluminium on the surface of the fibre. 6061 Al-boron fibre composites have been produced by diffusion bonding via the foil-fibre-foil process. However, the process is more commonly used to produce Ti based fibre reinforced composites. The process is cumbersome and obtaining high fibre volume fraction and homogeneous fibre distribution is difficult. The process is not suitable to produce complex shapes and components.

3.1c Physical vapour deposition: The process involves continuous passage of fibre through a region of high partial pressure of the metal to be deposited, where condensation takes place so as to produce a relatively thick coating on the fibre. The vapour is produced by directing a high power electron beam onto the end of a solid bar feed stock. Typical deposition rates are 5-10 $\mu \mathrm{m}$ per minute. Composite fabrication is usually completed by assembling the coated 


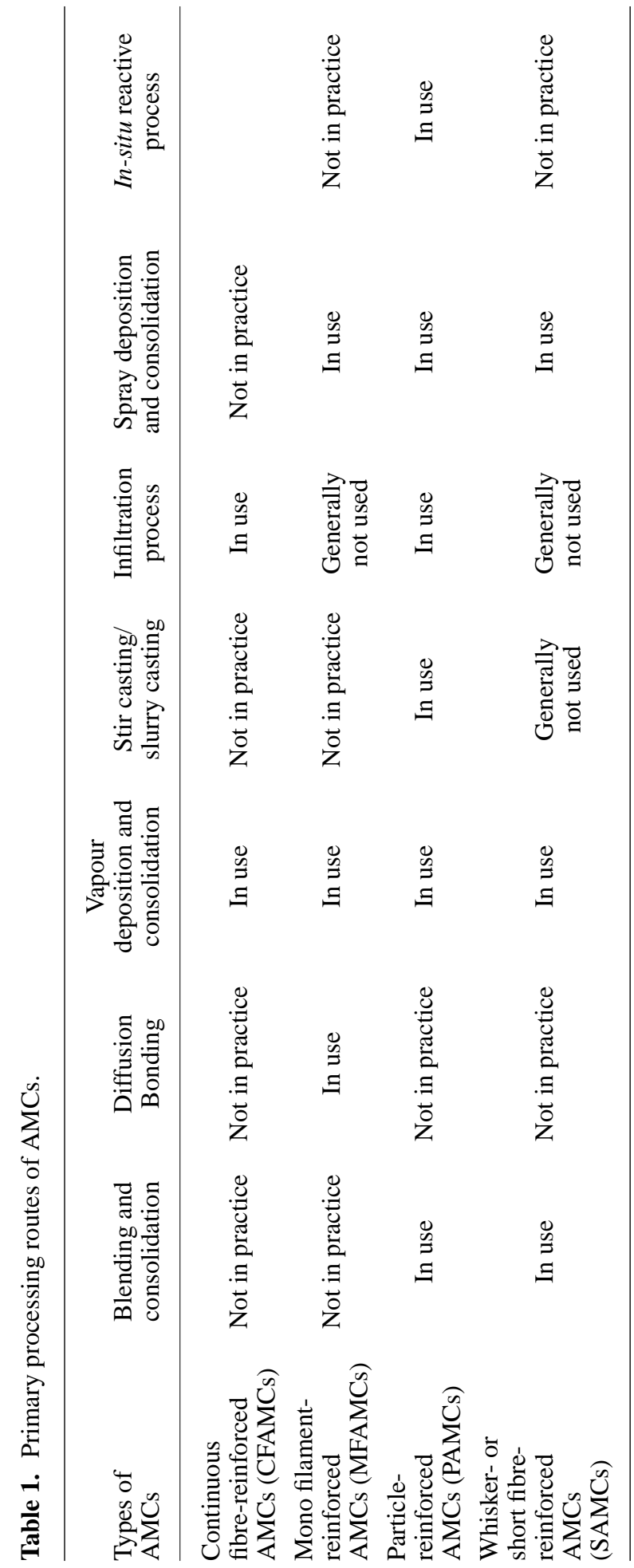


fibres into a bundle or array and consolidating in a hot press or HIP operation. Composites with uniform distribution of fibre and volume fraction as high as $80 \%$ can be produced by this technique.

\subsection{Liquid state processing}

3.2a Stir casting: This involves incorporation of ceramic particulate into liquid aluminium melt and allowing the mixture to solidify. Here, the crucial thing is to create good wetting between the particulate reinforcement and the liquid aluminium alloy melt. The simplest and most commercially used technique is known as vortex technique or stir-casting technique. The vortex technique involves the introduction of pre-treated ceramic particles into the vortex of molten alloy created by the rotating impeller. Lloyd (1999) reports that vortex-mixing technique for the preparation of ceramic particle dispersed aluminium matrix composites was originally developed by Surappa \& Rohatgi (1981) at the Indian Institute of Science. Subsequently several aluminium companies further refined and modified the process which are currently employed to manufacture a variety of AMCs on commercial scale.

Microstructural inhomogeneties can cause notably particle agglomeration and sedimentation in the melt and subsequently during solidification. Inhomogeneity in reinforcement distribution in these cast composites could also be a problem as a result of interaction between suspended ceramic particles and moving solid-liquid interface during solidification. Generally it is possible to incorporate upto $30 \%$ ceramic particles in the size range 5 to $100 \mu \mathrm{m}$ in a variety of molten aluminium alloys. The melt-ceramic particle slurry 11 may be transferred directly to a shaped mould prior to complete solidification or it may be allowed to solidify in billet or rod shape so that it can be reheated to the slurry form for further processing by technique such as die casting, and investment casting. The process is not suitable for the incorporation of sub-micron size ceramic particles or whiskers. Another variant of stir casting process is compo-casting. Here, ceramic particles are incorporated into the alloy in the semi solid state.

3.2b Infiltration process: Liquid aluminium alloy is injected/infiltrated into the interstices of the porous pre-forms of continuous fibre/short fibre or whisker or particle to produce AMCs. Depending on the nature of reinforcement and its volume fraction preform can be infiltrated, with or without the application of pressure or vacuum. AMCs having reinforcement volume fraction ranging from 10 to $70 \%$ can be produced using a variety of infiltration techniques. In order for the preform to retain its integrity and shape, it is often necessary to use silica and alumina based mixtures as binder. Some level of porosity and local variations in the volume fractions of the reinforcement are often noticed in the AMCs processed by infiltration technique. The process is widely used to produce aluminium matrix composites having particle/whisker/short fibre/continuous fibre as reinforcement.

3.2c Spray deposition: Spray deposition techniques fall into two distinct classes, depending whether the droplet stream is produced from a molten bath (Osprey process) or by continuous feeding of cold metal into a zone of rapid heat injection (thermal spray process). The spray process has been extensively explored for the production of AMCs by injecting ceramic particle/whisker/short fibre into the spray. AMCs produced in this way often exhibit inhomogeneous distribution of ceramic particles. Porosity in the as sprayed state is typically about $5-10 \%$. Depositions of this type are typically consolidated to full density by subsequent processing. Spray process also permit the production of continuous fibre reinforced aluminium matrix composites. For this, fibres are wrapped around a mandrel with controlled 
inter fibre spacing, and the matrix metal is sprayed onto the fibres. A composite monotype is thus formed; bulk composites are formed by hot pressing of composite monotypes. fibre volume fraction and distribution is controlled by adjusting the fibre spacing and the number of fibre layers. AMCs processed by spray deposition technique is relatively inexpensive with cost that is usually intermediate between stir cast and PM processes.

3.2d In-situ processing (reactive processing): There are several different processes that would fall under this category including liquid-gas, liquid-solid, liquid-liquid and mixed salt reactions. In these processes refractory reinforcement are created in the aluminium alloy matrix. One of the examples is directional oxidation of aluminium also known as DIMOX process. In this process the alloy of $\mathrm{Al}-\mathrm{Mg}$ is placed on the top of ceramic preform in a crucible. The entire assembly is heated to a suitable temperature in the atmosphere of free flowing nitrogen bearing gas mixture. $\mathrm{Al}-\mathrm{Mg}$ alloy soon after melting infiltrates into the preform and composite is formed.

Martin-Marietta's exothermic dispersion process or the $\mathrm{XD}^{\mathrm{Tm}}$ process is another in-situ technique for composite processing. $\mathrm{XD}^{\mathrm{Tm}}$ process is used to produce $\mathrm{TiB}_{2}$ reinforced aluminium matrix composites. The process is flexible and permits formation of both hard and soft phases of various sizes and morphologies that includes whiskers, particles and platelets in aluminium alloy matrices.

Gas-liquid reaction is also utilised to produce TiC reinforced aluminium matrix composites. For example, by bubbling carbonaceous gas like methane into Al-Ti melt kept at elevated temperature it is possible to produce $\mathrm{Al}-\mathrm{TiC}_{\mathrm{p}}$ composites. London and Scandinavian Metallurgical Company has developed an in-situ technique, which utilises reaction between mixed salts to produce a dispersion of fine $\mathrm{TiB}_{2}$ particles in an aluminium matrix. A major limitation of in-situ technique is related to the thermodynamic restrictions on the composition and nature of the reinforcement phase that can form in a given system, and the kinetic restrictions on the shape, size and volume fraction of the reinforcement that can be achieved through chemical reactions under a given set of test conditions.

\section{Effect of ceramic reinforcements on the behaviour of aluminium matrix in AMCs}

Presence of relatively large (more than 10\%) volume fraction of ceramic reinforcement (whisker/particle/short fibre/continuous fibre) profoundly effect the behaviour of aluminium matrix in aluminium matrix composites during manufacturing, heat treatment and their subsequent use in service. These changes include both intrinsic and extrinsic ones.

\subsection{Intrinsic effects}

Intrinsic effects include microstructural changes, heat treatment characteristics and thermal stresses. These changes significantly alter and expand the physical, mechanical and tribological property limits of aluminium alloys. Salient features of intrinsic effects caused by ceramic reinforcements are summarised below.

4.1a Solidification structure of AMCs: Presence of ceramic reinforcement can alter the solidification behaviour of aluminium alloys in several alloys. Ceramic reinforcement can serve as a barrier to diffusion of heat and solute, catalyse the heterogeneous nucleation of phases crystallising from the melt, restrict fluid convection, and induce morphological instabilities in the solid-liquid interface. Figure 2 shows the influence of interfibre spacing in an 
(b)

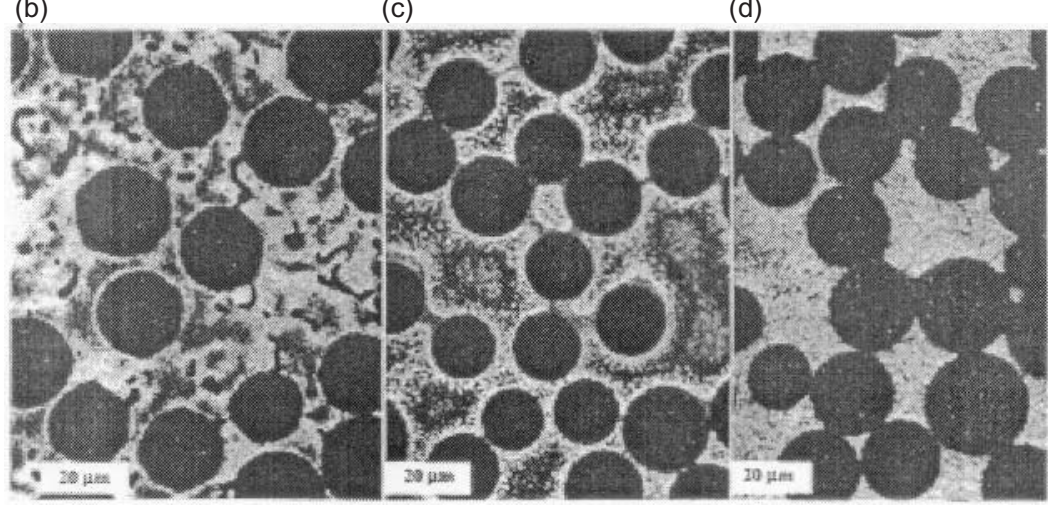

(a)

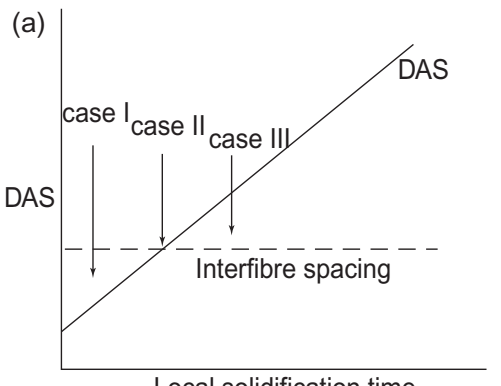

Local solidification time
Figure 2. Microstructure formation in the inter-fibre regions of an $\mathrm{Al}-4.5 \mathrm{Cu}$-alumina fibre composite. The primary phase morphology and the distribution of second phases depend upon the relative magnitudes of secondary arm spacing (DAS) and interfibre spacing. The microstructures shown in (b) through (d) correspond to three cases shown in (a).

alumina fibre (FP)-reinforced AlCu composite on the segregation of solute during solidification. When the secondary dendrite arm spacing (DAS) is smaller than the interfibre spacing (case 1, see figure 2a), the fibres do not influence the matrix solidification behaviour and normal coring patterns are observed (see figure $2 b$ ). When the scale of the matrix microstructure is comparable to the interfibre spacing (see figure $2 \mathrm{c}$ ), the secondary phases (e.g. eutectic) are deposited onto the fibre surface. Microprobe scans across the interfibre regions of the matrix confirm that solute content is highest at fibre surface and smallest in the centre of interfibre regions. Lastly, when the interfibre spacing is smaller than the secondary dendrite arm spacing (which can be controlled by the rate of external heat extraction), the segregation is reduced and less secondary phases are precipitated from the matrix (see figure $2 \mathrm{~d}$ ). Under these conditions, solute content of matrix is higher than that in unreinforced matrix.

It is well known that heterogeneous nucleation of primary phase crystals on the surface of some ceramic reinforcement reduces the matrix grain size. However, often grain sizes far in excess of the fibre or particle diameter are observed in cast aluminium matrix composites. Matrix grain size larger than reinforcement size indicates that fibres do not nucleate the primary phase during solidification. The grain size of $\mathrm{Al}-4.5 \mathrm{Cu}$ is not affected by $\mathrm{SiC}$ or alumina fibres. However, reaction sintered porous $\mathrm{TiC}$ reinforcement reduces the matrix grain size by several orders of magnitude. Similarly, heterogeneous nucleation of primary phases has been observed on alumina dispersions in $\mathrm{Al}-\mathrm{Cu}-\mathrm{Ti}$ alloy.

4.1b Effect of ceramic reinforcement on the age-hardening characteristics of aluminium alloys: The age hardening characteristics of aluminium alloys are generally modified by the introduction of ceramic reinforcement. These modifications depend on the matrix 
composition, the size, morphology and volume fraction of the reinforcement and the method of composite production. Some of the prominent modifications documented are detailed below.

(i) Composites based on $\mathrm{Al}-\mathrm{Cu}-\mathrm{Mg}$ alloy matrices exhibit accelerated ageing compared to the unreinforced alloys.

(ii) The peak temperature of $S_{1}$ precipitation was found to decrease with increasing volume fraction.

(iii) Room temperature ageing behaviour of $\mathrm{PM}$ processed $\mathrm{Al}-\mathrm{Cu}-\mathrm{SiC}_{p}$ composites is significantly different compared to that of cast and extruded composites.

(iv) The age hardening characteristics of the $6061 \mathrm{Al}$ alloy are considerably altered by the presence of fibres. Fibre array inhibits natural ageing.

(v) Presence of $\mathrm{TiC}$ particle retard ageing kinetics of $7075 \mathrm{Al}$ alloys.

Much of these changes in the age hardening characteristics of aluminium alloys due to the incorporation of ceramic reinforcement is attributed partly due to enhanced dislocation density. Large mismatch in the expansion coefficient of ceramic reinforcement and aluminium alloy matrix is responsible for increased density of dislocations. The increased density and consequent modifications in the age hardening response of aluminium alloys is an important intrinsic effect of ceramic reinforcements.

4.1c Thermal residual stresses: Aluminium matrix composites often experience fabrication temperature in excess of $500^{\circ} \mathrm{C}$, and large thermal residual stresses are included on cooling. Magnitude of thermal residual stresses developed is related to many variables including the type of reinforcement, volume fraction, diameter and aspect ratio. For example, thermal residual stresses (tensile) of more than $200 \mathrm{MPa}$ are present in the matrix of $\mathrm{Al}-30 \mathrm{vol} \% \mathrm{SiC}_{\mathrm{p}}$ composites. Mechanical behaviour of AMCs are profoundly effected by thermal residual stresses. Presence of residual stresses caused by ceramic reinforcement results a symmetrical yielding, and also affect fatigue and creep behaviour of AMCs.

\subsection{Extrinsic effects of ceramic reinforcement}

Incorporation of ceramic reinforcement in $\mathrm{Al}$ alloys leads to significant improvement in the sliding wear resistance of Al MMCs as measured by the pin-on-disc set up against a hardened steel disc and this is attributed to the intrinsic effect of SiCp. In recent years extrinsic effect of $\mathrm{SiC}$ reinforcement in $\mathrm{Al} \mathrm{MMCs}$ has been beneficially utilised in Al MMC brake disc/ brake pad tribocouple. When AMC brake disc slides against brake pad adherent tribolayer are formed on the surface of AMC disc at the contact region. Tribolayers thus formed further enhances the wear resistance of the AMC discs. Tribolayers consisting of mixed oxides are formed due to transfer of material from the brake pad on to the AMC disc during sliding. Material transfer and formation of tribolayers is primarily caused by the SiCp which stands proud of the matrix on the surface of AMC disc. Hence, tribolayer formation is caused by the extrinsic effect of $\mathrm{SiC}$ reinforcement in AMCs. Figure 3a shows the formation of tribolayer on AMC disc when slid against automobile brake pad. Figure $3 \mathrm{~b}$ shows the plots of the wear rate of AMC disc against automobile brake pad. In the same plot, wear rate of un-reinforced $\mathrm{Al}-\mathrm{Si}$ alloy and cast iron are also included. Evidently, figures $3 \mathrm{a}$ and $\mathrm{b}$ confirm the immense potential of AMCs as lightweight brake discs in transportation systems. This is one example where both intrinsic and extrinsic effects of $\mathrm{SiC}$ reinforcement in AMCs is fully exploited advantageously. 
(a)

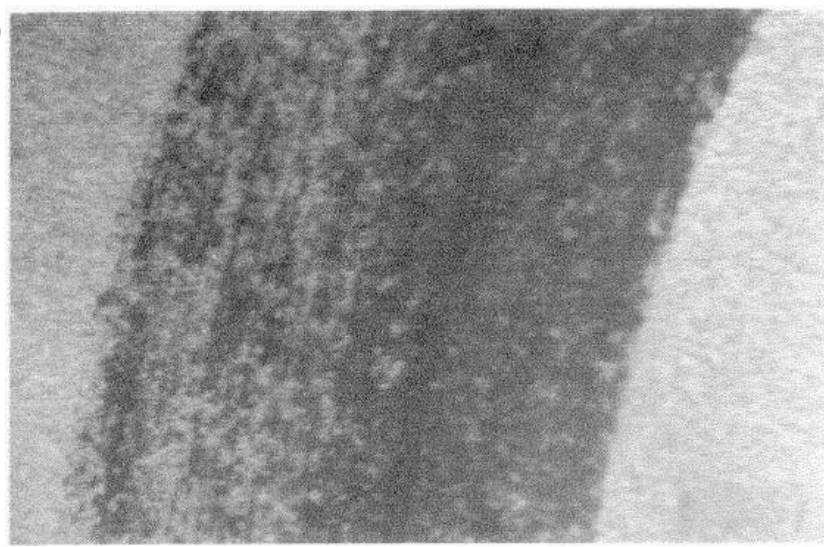

(b)

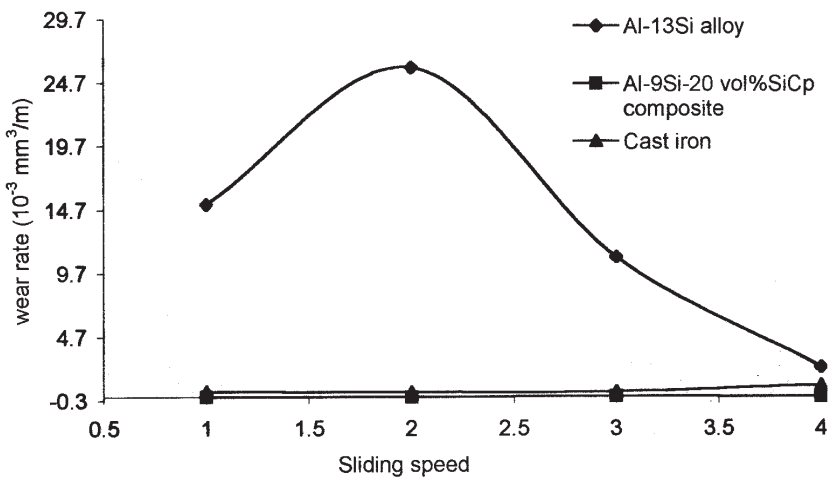

Figure 3. (a) Photograph showing the formation of tribolayer on the worn surface of AMC (disc) slid against brake pad (pin). (b) Sliding wear rates of unreinforced Al-alloy, SiCp reinforced $\mathrm{Al}$ composite and grey cast iron (disc) against brake pad (pin).

\section{Applications of AMCs}

AMCs now have a proven track record as successful "high-tech" materials in a range of applications. AMC utilisation provides significant benefits including performance benefits (component lifetime, improved productivity), economic benefits (energy savings or lower maintenance cost) and environmental benefits (lower noise levels and fewer air-borne emissions). Engineering viability of AMCs in a number of applications have been well-documented. AMCs having different type of reinforcements (whiskers/particles/short fibres/continuous fibres) and produced both by solid state and liquid state processing have found their way to many practical applications. Some of the newer and visible applications of different types of AMCs are detailed below.

\subsection{Particle reinforced aluminium matrix composites}

Of all the AMCs, particle reinforced AMCs constitutes largest quantity of composites produced and utilised on volume and weight basis. PAMCs are produced by PM stir cast/melt infiltration/spraying/in situ processing techniques at industrial level. Particulates of $\mathrm{SiC}$, $\mathrm{Al}_{2} \mathrm{O}_{3}, \mathrm{TiC}, \mathrm{TiB}_{2}, \mathrm{~B}_{4} \mathrm{C}$ have been used as reinforcements. PAMCs have been successfully used as components in automotive, aerospace, opto-mechanical assemblies and thermal management. PAMCs are in use as fan exit guide vane (FEGV) in the gas turbine engine (see figure 4), as ventral fins and fuel access cover doors in military aircraft. PAMCs are also 


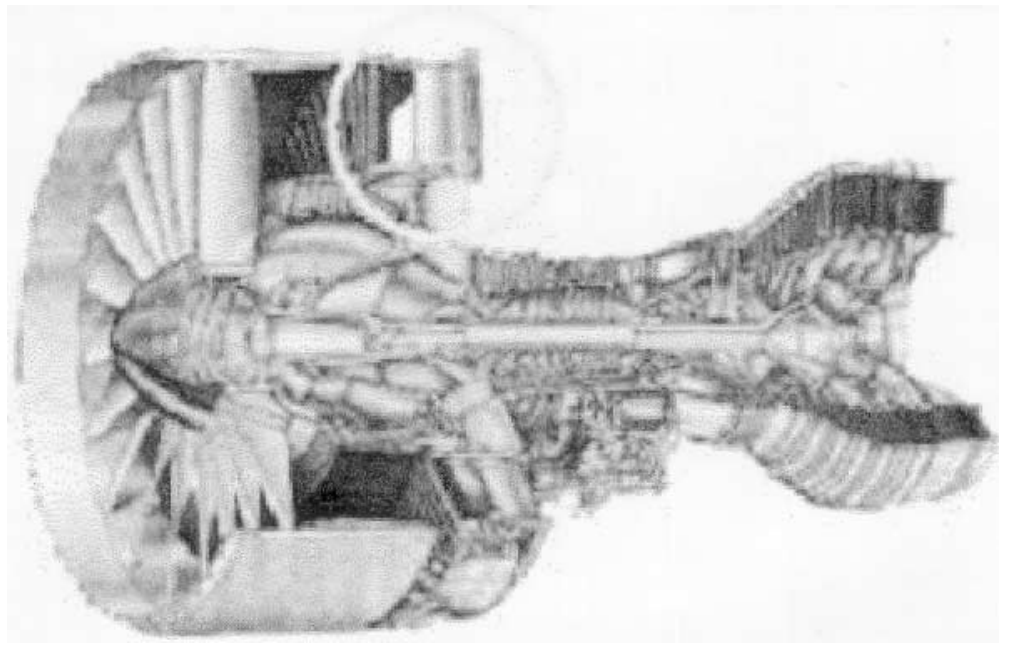

Figure 4. Fan exit guide vanes (FEGV) component made up of PAMCs used in $\mathrm{P}$ and $\mathrm{W}$ gas turbine engine.

used as rotating blade sleeves in helicopters (see figure 5). Flight control hydraulic manifolds made of $40 \mathrm{vol} \% \mathrm{SiCp}$ reinforced aluminium composites have been successfully used (see figure 6).

The most notable large size and high volume use of PAMCs is in braking systems of trains and cars. Presently AMC brake discs are extensively used in European Railways and are in use in certain models of passenger cars in U.S.A. A major car manufacturing company in Europe is planning to introduce AMC brake discs by the year 2004. Potential automotive applications of PAMCs include valves, crankshafts, gear parts and suspension arms.

Particle reinforced AMCs are in use as recreational products including golf club shaft and head, skating shoe, base ball shafts (see figure 7), horseshoes and bicycle frames. AMCs containing high volume fraction ceramic particles are being used as microprocessor lids and integrated heat sinks in electronic packaging. They are also in use as carrier plates and microwave housing.
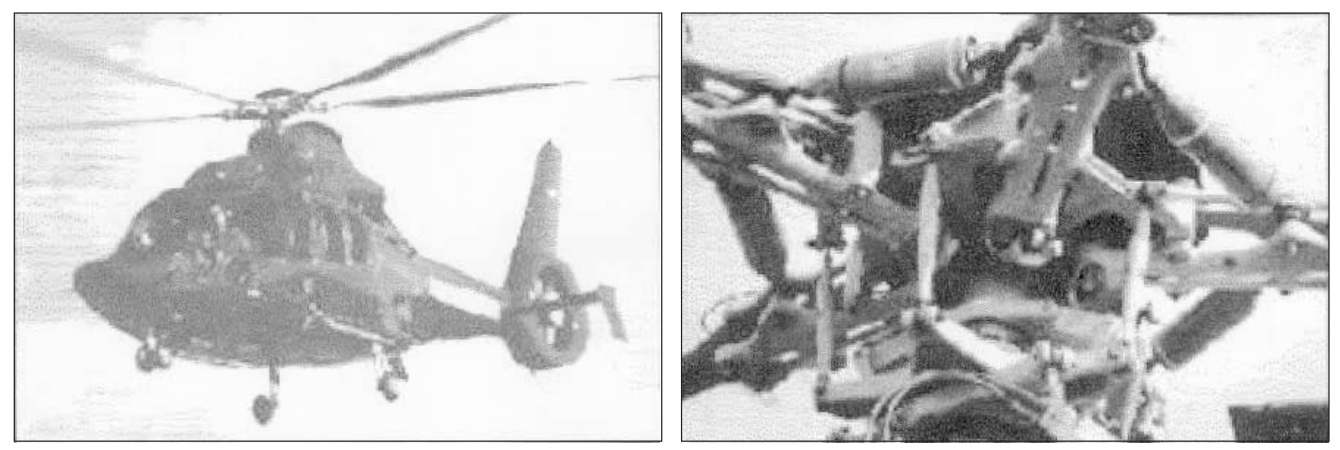

Figure 5. PAMC rotating blade sleeves used in helicopter. 


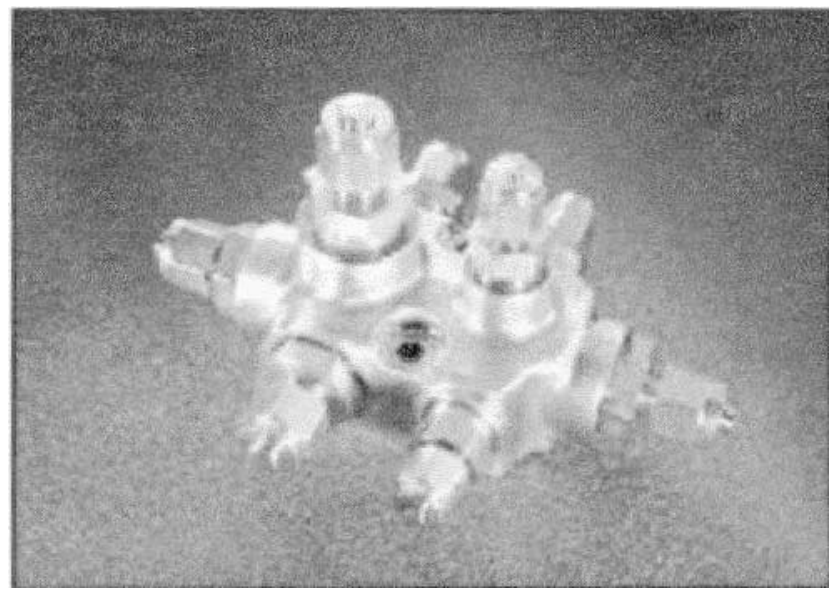

Figure 6. Near net shape PAMCs flight control hydraulic manifold.

\subsection{Whisker-and short fibre-reinforced aluminium matrix composites}

In the wake of greater health risks associated with the handling of ceramic whiskers, of late production of whisker-reinforced aluminium composites has been very limited. However, with appropriate safety measures, $\mathrm{SiC}$ whisker-reinforced aluminium matrix composites have been produced and used as track shoes in advanced military tanks. Use of whisker-reinforced AMCs as track shoes help in reducing the weight of the tank. Short fibre-reinforced AMCs are being used in piston and cylinder liner applications.

\subsection{Continuous fibre-reinforced aluminium matrix composites}

Carbon fibre (continuous) reinforced $\mathrm{Al}$ matrix composites have been used as antenna wave guides for the Hubble Space Telescope. Here, composites provide high dimensional accuracy, high thermal and electrical conductivity with no outgassing oxidation resistance. 6061 Al-boron fibre (continuous) composites have been used as struts in main cargo bay of space shuttle (see figure 8). More recently $3 \mathrm{M}^{\mathrm{Tm}}$ has developed alumina fibre (continuous) reinforced aluminium composites. Compared to high strength steel, CFAMCs developed by $3 \mathrm{MTm}$ offers equivalent strength at less than half the density and retains its strength to $300^{\circ} \mathrm{C}$ and beyond. Composites possess four times the electrical conductivity of steel or half that of pure aluminium. These composites have been targetted for several functional

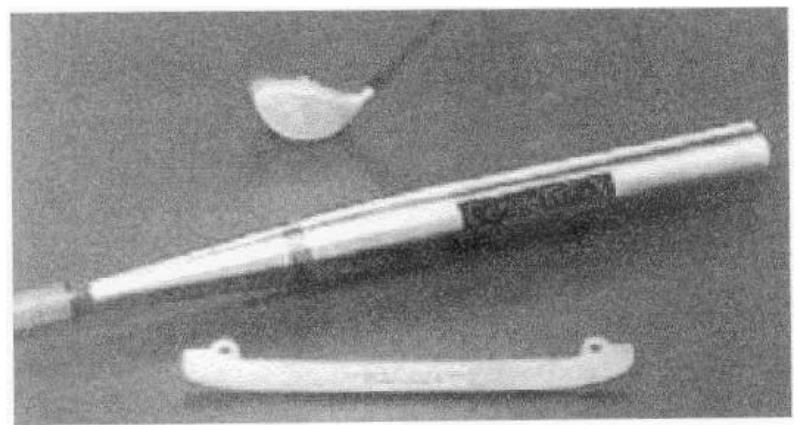

Figure 7. Recreational products made of PAMCs 


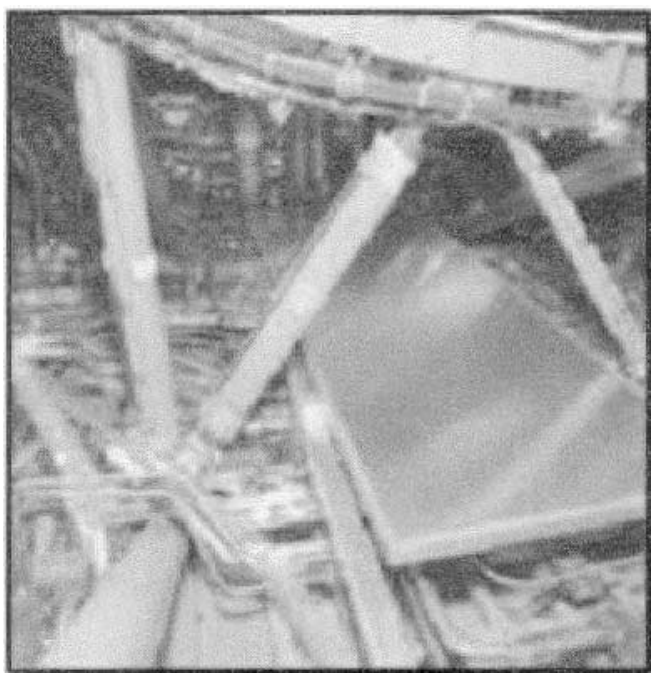

Figure 8. Continuous fibre-reinforced AMCs as struts used in main cargo bay of space shuttle.

applications including: (a) Core of an overhead electrical conductor; (b) automotive push rods; (c) flywheels for energy storage; (d) retainer rings for high-speed motors; and (e) brake callipers.

AMCs provide benefits in volume critical flywheel applications. Use of AMCs enable smaller flywheels compared to polymer composites (see figure 9). Thin walled retainer rings of AMCs provide excellent advantages in high-speed motors. AMC retainer rings can resist very high rotational speeds and still maintain their precise shape (figure 10). Brake callipers made of CFAMCs offer the following advantages compared to cast iron brake callipers (figure 11).

(1) Increased damping.

(2) Reduced unsprung weight.

(3) Increased fuel efficiency.

(4) Improved performance, handling and ride.

(5) Cross-platform utilisation.

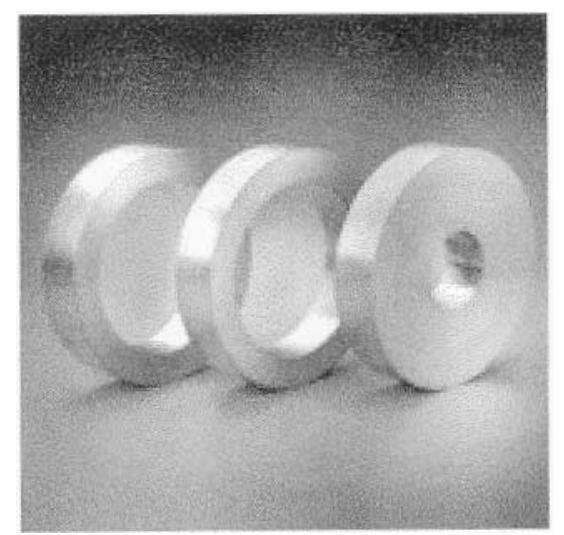

Figure 9. Alumina fibre-reinforced AMC flywheels. 


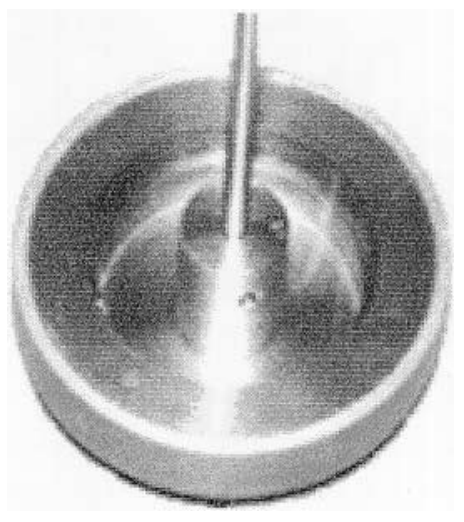

Figure 10. Alumina fibre-reinforced AMC retainer ring used in high-speed motors.

\section{Challenges and opportunities}

Several challenges must be overcome in order to intensify the engineering usage of AMCs. Design, research and product development efforts and business development skills are required to overcome these challenges. In this pursuit there is an imperative need to address the following issues.

- Science of primary processing of AMCs need to be understood more thoroughly, especially factors affecting the microstructural integrity including agglomerates in AMCs.

- There is need to improve the damage tolerant properties particularly fracture toughness and ductility in AMCs.

- Work should be done to produce high quality and low cost reinforcements from industrial wastes and by-products.

- Efforts should be made on the development of AMCs based on non-standard aluminium alloys as matrices.

- There is a greater need to classify different grades of AMCs based on property profile and manufacturing cost.

- There is an urgent need to develop simple, economical and portable non-destructive kits to quantify undesirable defects in AMCs.

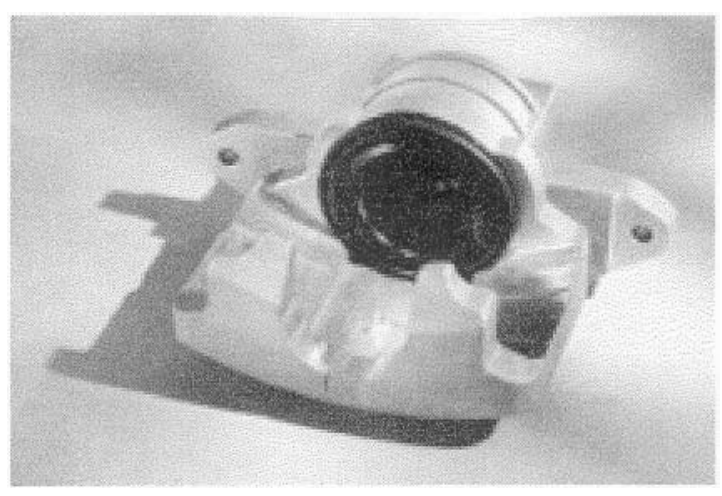

Figure 11. Alumina fibre-reinforced AMC calipers. 
- Secondary processing is an important issue in AMCs. Work must be initiated to develop simple and affordable joining techniques for AMCs. Development of less expensive tools for machining and cutting AMCs is of great necessity.

- Work must be done to develop re-cycling technology for AMCs.

- There must be more consortium/networking type approaches to share and document wealth of information on AMCs.

There exist tremendous opportunities to disseminate several high profile success stories on the engineering applications of AMCs amongst the materials community. AMCs must be looked upon as materials for energy conservation and environmental protection. These twin issues must create awareness at the government and policy formulators level and work to increase market acceptance by disseminating information on the outstanding potential of AMCs.

\section{References}

Asthana R 1998 Solidification processing of reinforced metals (Trans. Tech. Publ.)

Clyne T W (ed.) 2000 Comprehensive composite materials, Vol. 3. Metal matrix composites (ser. eds) A Kelly, C Zweben (Oxford: Pergamon)

Clyne T W 2001 Metal matrix composites: Matrices and processing. In Encyclopedia of materials science and technology (ed.) A Mortensen (Elsevier)

Clyne T W, Withers P J 1993 An introduction to metal matrix composites (Cambridge: University Press)

Lloyd D J 1999 Particle reinforced aluminium and magnesium matrix composites. Int. Mater. Rev. 39: $1-23$

Maruyama B 1998 Progress and promise in aluminium metal matrix composites. The AMPTIAC NewsLett. 2(3):

Surappa M K, Rohatgi P K 1981 Preparation and properties of aluminium alloy ceramic particle composites. J. Mater. Sci. 16: 983-993 